\begin{tabular}{|l|l|}
\hline Postprint Version & 1.0 \\
\hline Journal website & $\begin{array}{l}\text { http://journals.Iww.com/journalpatientsafety/Abstract/2011/12000/The_Nature_ } \\
\text { and_Causes_of_Unintended_Events.8.aspx }\end{array}$ \\
\hline Pubmed link & $\underline{\text { http://www.ncbi.nlm.nih.gov/pubmed/22064626 }}$ \\
\hline DOI & $10.1097 /$ PTS.0b013e3182388f97 \\
\hline
\end{tabular}

This is a NIVEL certified Post Print, more info at http://www.nivel.eu

\title{
The Nature and Causes of Unintended Events Reported at 10 Internal Medicine Departments
}

\author{
LUBBERDING, SANNE MSC*; ZWAAN, LAURA MSC†; TIMMERMANS, DANIËLLE R.M. PHD†; WAGNER, \\ CORDULA PHD*†
}

Author Information

From the *NIVEL, Netherlands Institute for Health Services Research; and†EMGO Institute for Health and Care Research, Department of Publicand Occupational Health, VU University Medical Center, Amsterdam, the Netherlands.

Correspondence: Sanne Lubberding, MSc, NIVEL, Netherlands Institute for Health Services Research, PO Box 1568, 3500 BN Utrecht, the Netherlands (e-mail: s.lubberding@vumc.nl).

The authors disclose no conflict of interest.

The Dutch Patient Safety Research Program has been initiated by the Dutch Society of Medical Specialists (Orde van Medisch Specialisten), with financial support from the Ministry of Health, Welfare, and Sport. The program is carried out by EMGO Institute/VU University Medical Center and NIVEL.

This article was presented at the ISQUA conference in Dublin, October 12, 2009.

\begin{abstract}
Objective: This study aimed to examine the nature and causes of unintended events (UEs) at internal medicine departments (IMD).

Methods: An observational study was conducted at 10 IMDs in 8 Dutch hospitals. The study period per participating department was 5 to 14 weeks. During this period, staff were asked to report all UEs concerning patient safety. To identify underlying root causes, experienced researchers analyzed the reports using a standardized root cause analysis method called PRISMA medical.

Results: Hospital staff reported 625 UEs. Medication-related UEs were the most reported events (42\%). Of all reported UEs, $12 \%$ involved the collaboration between the IMD and other departments within the hospital.

On the basis of the 625 UEs, 920 root causes were identified. The mean (SD) number of root causes per incident was 1.47 (0.68). Human root causes were related to 83.2\% of the UEs, organizational root causes were related to $15.7 \%$, technical root causes were related to $7 \%$, and other root causes were related to $8.6 \%$ of the UEs.

More than half of the reported UEs reached the patient (62\%), with suboptimal care as the most frequently occurring consequence (44.7\%). Physical injury occurred in $10.3 \%$ of the UEs.

Conclusions: Hospital staff reporting UEs seems to be a good method for gaining insight into the types of UEs that occur at hospital departments. Although many UEs had human causes, identifying technical and organizational causes is important for the development of successful
\end{abstract}


improvement strategies considering their contribution to human error. Important targets for these strategies are the medication process and collaboration within the hospital.

In recent years, patient safety has received considerable attention in international research, and with good reason. Much of the previous research has used reviews of medical records to establish the number of adverse events (AEs) in hospitals. They showed that adverse events occurred in between $2.9 \%$ and $16.6 \%$ of all hospital admissions.1-6 Unintended events (UEs) in hospitals concerning patient safety are proven to occur frequently, and many are considered preventable.7-10 In contrast to adverse events, UEs are a broader group of events - including near-misses — that might, but do not necessarily, result in physical harm for patients. They may vary from computers that are out of order, to events leading to serious injury or death of a patient.

The internal medicine department (IMD) is characterized by older patients who experience multiple and complex diseases. Research shows that elderly patients experience more adverse events than younger patients do.1,8,11,12 Moreover, nearly all patients treated at the IMD are medication-reliant. Medicationrelated adverse events are one of the most common types of adverse and UEs identified in previous studies.10-12 As a result, several studies have focused solely on medication adverse events to identify their incidence and preventability and their relation to medication error.13,14 In a prospective study on adverse drug events, Leape et al 15 investigated the relevance of a system approach in identifying underlying contributors to adverse drug events. They concluded that the analysis and correction of underlying system faults is more likely to result in enduring changes and significant error reduction.

Earlier studies 16-18 focused on different methods to identify adverse or UEs and did not provide insight into the causes of the identified events. Prospective studies that did identify causes of UEs included all hospital departments, restricted their research to adverse drug events or continuous quality improvement in the ambulatory setting, or focused on the intensive care unit (ICU).13-15,19-22 These studies showed that patient safety events often have multiple causal factors related to human and organizational factors.21,22 Cullen et al 23 concluded that there was no difference in the likelihood that preventable drug events occur in ICUs versus non-ICUs, which underlines the importance of identifying causes of UEs in the IMD to improve patient safety in this department. In this study, we used a system approach to identify underlying factors that contribute to the origination of UEs. We investigated UEs rather than AEs to obtain a broad spectrum of events occurring at the IMD that may be a threat to patients. The general assumption is that causes of UEs are similar to causes of AEs and represent systematic flaws in the organization. When several UEs occur concurrently, this could lead to a major event for the patient because the system might not be able to intercept these faults. Therefore, the goal is to improve the system before major events occur and not to trust the resilience of the system. Because UEs do not always have as severe consequences as AEs do, the assumption is that the barrier to reporting them is lower. Besides, the higher frequencies of UEs possibly give a better insight into relevant causes and contributing factors and therefore provide useful and relevant information.

The goal of our study was to examine the nature and causes of UEs to gain insight into the chain of events leading up to a UE and the consequences. To do so, incident reporting data are collected and analyzed using a root cause analysis method.

Our research aims were as follows:

1. to gain insight into the nature of UEs occurring in the IMD,

2. to identify the causes underlying these UEs and the possible variation between departments and between UE types, and

3. to identify the consequences of the reported UEs and their distribution across UE types.

\section{METHODS}

\section{Study Design and Setting}

From January 2007 until February 2008, an observational study was conducted to examine the causes of UEs at 10 IMDs of 8 hospitals in the Netherlands. These were 2 university hospitals, 3 tertiary teaching hospitals, and 3 general hospitals. Unintended events were defined as all events, no matter how trivial or 
commonplace they seemed, that were unintended and could have harmed or did actually harm the patient.24

Internal medicine departments of 16 hospitals were selected for participation, of which 8 declined to participate. The participating IMDs are a good reflection of IMDs in the Netherlands, based on type of hospital, their dispersion across the Netherlands (city/rural area), and their size. The enrollment of the departments was phased. The study period per IMD was 5 to 14 weeks, depending on the reporting speed.

All health care providers working at the department (nurses, physicians) and clerks were asked to report all UEs that occurred, both when they were involved in an event and when they witnessed an event. Before the study, an introductory presentation (oral and written) was given to inform the staff about the aim and procedure of the study.

\section{Data Collection}

Data were collected through the use of pocket-sized UE report cards and UE report forms. On the report card, the UE reporter wrote his/her name, the date and time of the occurrence, and the discovery of the UE. Subsequently, the UE was described. The report forms were more detailed and included additional questions about the place of discovery, the health care providers involved, and patients' characteristics. In some hospitals, UEs were reported by using the hospitals' electronic incident reporting system. Agreements were made with the hospitals' existing incident committees, so UEs did not need to be reported twice. Completed cards and forms were gathered in a locked patient safety mailbox available at the ward, from where a member of the research team collected them.

Subsequently, the researcher that collected the report cards interviewed the reporter about the reported incident. To ensure a good comparability between the interviews, the researchers held regular meetings in which the interview method was discussed. The interviews provided crucial information concerning the causes and outcomes of the UE. In this interview, questions were asked about the context of the UE, the work instructions, and any technical aspects that might have been of influence. The information obtained was limited to the information the reporter could provide; no other individuals or departments were approached to supply information. The researchers strived to get between 50 and 100 UE reports per IMD.

\section{ANALYSIS}

\section{Classifying UEs}

The UEs were classified into 1 of 8 types based on literature and empirical data after completing the study: (1) materials and equipment, (2) diagnosis and treatment, (3) medication, (4) protocols and regulations, (5) incorrect data and substitutions, (6) collaboration with resident physicians and consultants, (7) collaboration with other departments, and (8) other.

\section{Identifying causes of UEs}

To identify the causes of the UEs, data were analyzed using PRISMA medical (Prevention and Recovery Information System for Monitoring and Analysis) by 2 researchers (S.L. and L.Z.).25,26 Both were trained in using the PRISMA method. The corresponding taxonomy for classifying the root causes of UEs, the Eindhoven Classification Model (ECM), has been accepted by the World Alliance for Patient Safety of the World Health Organization (Table 1).27,28 The PRISMA method is based on Reason's system approach to human error, with specific attention for latent and active conditions.29,30 PRISMA identifies 5 main categories: human, organizational, technical, patient-related, and other factors. These 5 main categories are subdivided into 20 subcategories in the ECM. Organizational and technical factors are considered latent conditions, whereas the human factors are considered to be active errors. The human section of the ECM is based on the Skills-Rules-Knowledge approach by Rasmussen.31 This is a basic model of human error based on 3 levels of behavior: skill-based, rule-based, and knowledge-based. Skill-based behavior is based on automaticity; little or no conscious attention is needed to execute the task. Rule-based behavior involves an action based on the application of existing rules in familiar situations. Knowledge-based behavior involves the application of existing knowledge in managing nonfamiliar situations.31 


\section{[TABLE 1$]$}

To obtain a valid PRISMA profile of a department, the developers of the PRISMA method advised a minimum of 50 reported UEs. The interrater reliability of formulating root causes in causal trees and classifying the root causes with the ECM was examined in a previous article. The agreement for formulating root causes was good (2.0 on a scale from 0 to 3 ). The interrater reliability for the number of root causes used in the causal tree was moderate ([kappa] $=0.46)$ and substantial for classifying root causes at all levels of the ECM $(0.63<[\mathrm{kappa}]<0.71) .32$

\section{Consequences of UEs}

The consequences of the UEs were identified for UEs that "reached the patient" (patient events). Non patient events include safety and environment issues or near-misses. The consequences of UEs that reached the patient were derived from the interviews with the UE reporter. The consequences the UE reporter identified were categorized into 8 categories: (1) extra interventions, (2) physical injury, (3) prolonged stay (>24 hours), (4) mental harm, (5) pain, (6) discomfort, (7) suboptimal care, and (8) other. Because UEs could have multiple consequences, all consequences identified by the UE reporter were categorized.

\section{Statistical Analysis}

The data from the reported UEs were summarized by using frequency tables and descriptive statistics in SPSS 14.0 (SPSS, Chicago, IL). All data were analyzed using all reported unintended events $(\mathrm{N}=625)$, except for the outcomes of UEs over UE types. These outcomes $(n=422)$ were analyzed using only UEs with consequences for the patient $(n=389)$.

\section{RESULTS}

\section{Nature of UEs}

Overall, 625 UEs were reported by medical staff. The number of UEs per department ranged from 44 to 99, with a mean (SD) of 63 (15.672). Not all departments reached the minimum of 50 UEs owing to the dependence on hospital staff to report UEs. Most UEs (74\%) were discovered by a health care professional (nurses and physicians). In 6\% of the UEs, the patient or family discovered the incident and reported it to hospital staff, who then completed a UE report card. Furthermore, UEs were discovered during a routine check according to protocol in $15 \%$ of the cases. The other $5 \%$ of the UEs were discovered in various other ways.

Nurses reported more UEs than physicians did, whereas in $42 \%$ of the cases, the reporter of the UE was directly involved or a witness to the incident. Table 2 shows the characteristics of the reported UEs.

\section{[TABLE 2 ]}

Medication-related UEs were the most frequently $(41.9 \%, \mathrm{n}=262)$ reported UE type, followed by “collaboration with other departments" $(12.2 \%, \mathrm{n}=76)$ and "diagnosis and treatment" $(11.2 \%, \mathrm{n}=70)$. Of all UEs, $62.2 \%$ reached the patient. Table 3 shows examples of reported UEs per UE type.

\section{[TABLE 3 ]}

\section{Root Causes of UEs}

On the basis of the 625 incidents, 920 root causes were identified and analyzed using the ECM. The mean (SD) number of root causes per incident was $1.47(0.68)$.

In an average of $83.2 \%$ of all reported UEs (range, 68.6\%-92.8\%), 1 or more human factors were identified. An average of $15.7 \%$ was related to 1 or more organizational factors (range, $2.9 \%-29.1 \%$ ), and 1 or more technical factors contributed to an average of $7 \%$ of the UEs (range, $0 \%-15.9 \%$ ).

\section{Distribution of Root Causes Over Subcategories and Departments}

\section{[FIGURE 1]}

The most common root cause subcategory is HRI (human intervention), appearing in $52.6 \%$ of the cases. The 2 next most common subcategories by frequency also involved human factors: HRV (human verification, 21.3\%) and H-Ex (human external, 19.2\%). 
The organizational factor that contributed most frequently to the reported UEs in the study period is culture (OC, 3.7\%). The most frequently occurring technical factor is design (TD, 4.6\%).

As Figure 1 shows, the largest differences between the departments also occur in the categories OC, TD, and the 3 human root cause categories HRV, HRI, and H-Ex.

\section{Variation of Root Causes Between UE Types}

To gain insight into the relation between causes of UEs and types of incidents, we examined the percentage of technical, human, and organizational classified root causes per type of UE (Table 4).

\section{[TABLE 4 ]}

Human root causes were the most frequent contributing root causes to each of the 8 UE types. Unintended events related to "materials and equipment" are caused by technical, organizational and human contributing factors. The UE types where organizational factors also played an important role are "collaboration with other departments," "diagnosis and treatment," and "protocols and regulations."

\section{Outcomes of the Reported UEs}

Table 5 shows the consequences for patients of UEs. Only UEs that reached the patient were used in this analysis $(n=389)$. The most frequent consequence for patients was suboptimal care, that is, care that did not go according to plan or protocol, for example, not receiving prescribed medication, resulting in no physical harm to the patient. This type of consequence occurred in 174 UEs (44.7\%). Of all UEs in this analysis, $10.3 \%$ resulted in physical injury for the patient.

\section{[TABLE 5 ]}

Figure 2 shows outcomes of UEs related to UE type. The outcomes of UEs vary widely across the different UE types. Unintended events concerning the collaboration with other departments result most often in discomfort for the patient (31.8\%) and rarely in physical injury (2.5\%), whereas medication-related UEs often result in suboptimal care (64.4\%) and unknown consequences (48.3\%).

\section{[FIGURE 2 ]}

Diagnosis and treatment UEs often have prolonged stay (42.9\%) and physical injury (22.5\%) as outcomes, whereas UEs regarding materials and equipment in this study never result in prolonged stay (0\%) or mental harm (0\%), but often in extra interventions (17.4\%). Unintended events concerning incorrect data and substitutions have only 3 different types of outcomes: extra interventions (1.4\%), suboptimal care (1.1\%), and unknown consequences (6.9\%). Unintended events regarding protocols and regulations never result in pain in this study (0\%) but often in extra interventions (13\%). Unintended events concerning the collaboration with residents/specialists often result in mental harm (11.1\%), but never in physical injury (0\%).

\section{DISCUSSION}

\section{Main Findings}

The objective of this study was to gain insights into the nature and causes of UEs at 10 IMDs, as well as their outcomes. To obtain this information, a large number of UEs were reported by hospital staff. Results showed that most of the reported UEs were classified as medication related, including the prescription, preparation, and administration of medication to the patient by a hospital caregiver. Besides medicationrelated UEs, a large number of UEs involved the collaboration with other hospital departments, such as the pharmacy.

Human root causes were the main category of error in the origination of UEs. Most of the reported incidents did not have severe consequences, with the most frequent outcome being suboptimal care, for example, receiving the wrong type of prescribed medication without any physical harm being done to the patient. Nevertheless, physical harm for the patient resulted from 1 in 10 UEs. 


\section{Interpretation}

The high frequency of medication-related UEs is not surprising because many patients on the IMD are medication reliant, and the medication process is complex, consisting of various steps. In addition, changes in medication policy are common during the period of admission, increasing the likelihood of errors.

The results show that the collaboration between departments is also an important category of UEs. To adequately care for its patients, the IMD is dependent on the pharmacy, radiology, laboratory, and consulting services. Because the operating procedures between these departments often differ, and the departments are not always familiar with each other's procedures, communication errors and inconsistencies may occur, leading to UEs.

The finding that the causes of UEs were mainly human could partially be explained by the fact that a human action is usually necessary for an error to occur. It is almost impossible for an UE to be completely related to only latent conditions such as technical and organizational factors. Unintended events therefore often relate to human causes or a combination of human causes and latent factors.

Although many UEs did not have severe consequences, the high percentage of suboptimal care as a consequence indicates that the quality of care can be improved and that the number of risk moments could be reduced. Consequences of UEs are most often related to medication incidents and the diagnosis and treatment of a patient. Although most of the reported incidents are medication-related UEs, this finding could also be explained by the impact these types of events have on a wider range of factors affecting the patient, in contrast to other types of UEs. For instance, a misdiagnosis of a patient might lead to incorrect treatment and therefore to several different consequences for the patient resulting from that treatment.

\section{Comparison With Previous Studies}

The present study shows some similarities with previous event reporting studies. As in this study, Nuckols et al 10 and Olsen et al 33 also found that nurses made most of the event reports. The high number of medication-related UEs is also consistent with findings in other studies.2,10,11,19,20,34 The number in our study was even higher than previously found. A systematic review of adverse event literature by de Vries et al 34 showed that drug-related adverse events are the second leading category of adverse events (ranging from $11 \%$ to $24 \%$ ). Only surgery-related adverse events occur more often. Milch et al 19 also found that the laboratory was the most common reported event within their main category of "nonmedication clinical events," which relates to our finding that the collaboration with other departments is the second most reported UE type.

Nevertheless, it is difficult to compare the results of the various studies, owing to their differences in method. For instance, Plews-Ogan et al 20 used a systems analysis as part of a model for continuous quality improvement in the ambulatory setting. However, they do not describe the root causes in detail, focusing rather on intervention methods to improve quality based on an incident type.

Nevertheless, the present study provides a valuable insight into the causes and outcomes of UEs and relevant starting points for improvements.

\section{Implications for Practice}

The results of this study indicate that patient care can be improved and that there are differences in quality between departments. It is recommended that improvement strategies focus on redesigning the environment in which human errors occur. Technical and organizational factors should certainly be addressed when attempting to reduce human errors, given the influence of these factors on the occurrence of human errors. A number of human causes of UEs could possibly have been prevented had more systematic organizational or technical solutions, such as a structured communication checklist between departments and hospital staff, existed. This complies with Reason's 29,30 system approach. Important areas of hospital care where improvement is desired include the medication process and the collaboration between departments. Improvements in these areas might include introducing more barriers, that is, reminders, in the care process, enhancing the familiarity of hospital personnel with current hospital protocols, critically evaluating the organization's care processes and remove illogical or unnecessary steps, or implementing structured handover processes.

The precise implementation of improvements depends on context-specific aspects (e.g., problem perception, expected advantages of the improvement, and cost-effectiveness). Therefore, the improvements should apply to problems and causes that the department or hospital wishes to address. 


\section{Limitations}

There are several limitations to our study. Perhaps the UEs identified do not fully represent all UEs that occurred at the participating departments during the study period. Some of the hospital staff stated that they were unwilling to report the same type of event a second time. In addition, some differences in the willingness to report events across the participating hospitals may exist. It is, however, impossible to estimate to what extent UEs are missing, and whether the missing UEs are of a specific type. However, after completing the study, we verified the reported events with the participating departments during a presentation of the results, and it was confirmed that the UEs reported were a good representation of the UEs occurring at their department. Nevertheless, the generalizability of the results may be influenced by factors that affect reporting behavior of hospital staff; for instance, their workload, the culture within the hospital, but also the prevailing legal climate. These factors may differ between hospitals, departments, and countries. However, the results from the present study provide no reasons to assume that the nature and root causes of UEs at other IMDs would differ from the UEs reported at the departments in this study.

Another limitation to our study is that the researchers had to rely on the information provided by the UE reporter. It is possible that UE reporters did not provide all the information they had to the researcher because they did not realize its importance or they did not perceive the contribution of some factors to the incident they reported. We have tried to minimize this possibility by using well-trained interviewers.

Another factor that could have influenced our results is that most incidents were reported by nurses and thus relate to care provided by nurses.

Lastly, because there were no specific a priori hypotheses regarding the outcomes before the start of the study, the analysis could be considered as hypothesis generating.

\section{CONCLUSIONS}

The reporting by hospital staff of UEs seems to be a good method for gaining insight into the UEs occurring at hospital departments. Most of the contributing factors were identified as human causes, although organizational and technical factors also had an important influence. Important areas for improvement are as follows: the prescription, preparation, and administration of medication to patients and the collaboration between departments as well as between nurses and physicians within the hospital. Starting points for improvement strategies could be to include more barriers, that is, reminders, in the care process or to critically evaluate the organization's care processes and remove illogical and unnecessary steps, thereby reducing the risk of human errors arising.

\section{ACKNOWLEDGMENTS}

The authors thank the participating hospitals for their willingness to participate in the study and the staff of the participating departments for their cooperation in conducting the study. The authors also thank Diethe Crassee, Lilian Hoonhout, Inge van Noord, and Inge van Wagtendonk for their contribution to the data collection.

\section{REFERENCES}

1. Zegers $\mathrm{M}$, de Bruyne de $\mathrm{MC}$, Wagner $\mathrm{C}$, et al.. Adverse events and potentially preventable deaths in Dutch hospitals: results of a retrospective patient record review study. Qual Saf Health Care. 2009; 18; 297-302.

2. Thomas EJ, Studdert DM, Burstin HR, et al.. Incidence and types of adverse events and negligent care in Utah and Colorado. Med Care. 2000; 38: 261-271.

3. Schioler T, Lipczak H, Pedersen BL, et al.. Incidence of adverse events in hospitals. A retrospective study of medical records [in Danish]. Ugeskr Laeger. 2001; 163: 5370-5378.

4. Vincent $C$, Neale G, Woloshynowych M. Adverse events in British hospitals: preliminary retrospective record review. BMJ. 2001; 322: 517-519.

5. Davis P, Lay-Yee R, Briant R, et al.. Adverse events in New Zealand public hospitals: 1. Occurrence and impact. N Z Med J. 2002; 115: U271.

6. Michel P, Quenon JL, De Sarasqueta AM, et al.. Comparison of three methods for estimating rates of adverse events and rates of preventable adverse events in acute care hospitals. BMJ. 2004; 328: 199. 
7. Sinopoli DJ, Needham DM, Thompson DA, et al.. Intensive care unit safety incidents for medical versus surgical patients: a prospective multicenter study. J Crit Care. 2007; 22: 177-183.

8. Brennan TA, Leape LL, Laird NM, et al.. Incidence of adverse events and negligence in hospitalized patients. Results of the Harvard Medical Practice Study 1. N Engl J Med. 1991; 324: 370-376.

9. Wilson RM, Runciman WB, Gibberd RW, et al.. The quality in Australian health care study. Med J Aust. 1995; 163: 458-471.

10. Nuckols TK, Bell DS, Liu H, et al.. Rates and types of events reported to established incident reporting systems in two US hospitals. Qual Saf Health Care. 2007; 16: 164-168.

11. Leape LL, Brennan TA, Laird N, et al.. The nature of adverse events in hospitalized patients: results of the Harvard Medical Practice Study II. N Engl J Med. 1991; 324; 377-384.

12. Baker GR, Norton PG, Flintoft V, et al.. The Canadian Adverse Events Study: the incidence of adverse events among hospital patients in Canada. CMAJ. 2004; 170: 1678-1686.

13. Bates DW, Boyle DL, Vander Vliet MB, et al.. Relationship between medication errors and adverse drug events. J Gen Intern Med. 1995; 10; 199-205.

14. Bates DW, Leape LL, Petrycki S. Incidence and preventability of adverse drug events in hospitalized adults. J Gen Intern Med. 1993; 8; 289-294.

15. Leape LL, Bates DW, Cullen DJ, et al.. Systems analysis of adverse drug events. JAMA. 1995; 274: 35-43.

16. Weingart SN, Ship AN, Aronson MD. Confidential clinician-reported surveillance of adverse events among medical inpatients. J Gen Intern Med. 2000; 15: 470-47.

17. Witham MD, Kendall PA. A prospective, physician self-reported adverse incident audit on a general medical unit. J Qual Clin Pract. 2001; 21: 61-65.

18. Nettleman MD, Nelson AP. Adverse occurrences during hospitalization on a general medicine service. Clin Perform Qual Health Care. 1994; 2; 67-72.

19. Milch CE, Salem DN, Pauker SG, et al.. Voluntary electronic reporting of medical errors and adverse events. An analysis of 92,547 reports from 26 acute care hospitals. J Gen Intern Med. 2006; 21: 165-170.

20. Plews-Ogan ML, Nadkarni MM, Forren S, et al.. Patient safety in the ambulatory setting. A clinicianbased approach. J Gen Intern Med. 2004; 19: 719-725.

21. Pronovost PJ, Thompson DA, Holzmueller CG, et al.. Toward learning from patient safety reporting systems. J Crit Care. 2006; 21; 305-315.

22. Nast PA, Avidan M, Harris CB, et al.. Reporting and classification ofpatient safety events in a cardiothoracic intensive care unit and cardiothoracic postoperative care unit. J Thorac Cardiovasc Surg. 2005; 130; 1137.

23. Cullen DJ, Sweitzer BJ, Bates DW, et al.. Preventable drug events in hospitalized patients: a comparative study of intensive care and general units. Crit Care Med. 1997; 25; 1289-1297.

24. Bhasale AL, Miller GC, Reid SE, et al.. Analysing potential harm in Australian general practice: an incident-monitoring study. Med J Aust. 1998; 169: 73-76.

25. Vuuren W, van Shea CE, Schaaf TW, et al.. The Development of an Incident Analyses Tool for the Medical Field. Eindhoven, the Netherlands: Eindhoven University of Technology; 1997.

26. Schaaf TW, van der Habraken MMP. PRISMA—Medical a Brief Description. Eindhoven, the Netherlands: University of Technology, Faculty of Technology Management, Patient Safety Systems; 2005.

27. World Health Organization Alliance for Patient Safety. Project to Develop the International Patient Safety Event Taxonomy: Updated Review of the Literature 2003-2005. Geneva, Switzerland: World Health Organization; 2005.

28. World Health Organization Alliance for Patient Safety. The Conceptual Framework of an International Patient Safety Event Classification: Executive Summary. Geneva, Switzerland: World Health Organization; 2006.

29. Reason JT. Managing the Risk of Organisational Accidents. Aldershot, UK: Ashgate; 1997.

30. Reason JT. Human Error. Cambridge, NY: Cambridge University Press; 1990.

31. Rasmussen J. Skills, Rules and Knowledge: signals, signs and symbols and other distinctions in human performance models. IEEE Trans Systems Man Cybernetics. 1983; 13: 257-266.

32. Smits M, Janssen J, Vet de R, et al.. Analysis of unintended events in hospitals: inter-rater reliability of constructing causal trees and classifying root causes. Int J Qual Health Care. 2009; 21; 292-300.

33. Olsen S, Neale G, Schwab K, et al.. Hospital staff should use more than one method to detect adverse events and potential adverse events: incident reporting, pharmacist surveillance and local real-time record review may all have a place. Qual Saf Health Care. 2007; 16: 40-44.

34. de Vries EN, Ramrattan MA, Smorenburg SM, et al.. The incidence and nature of in-hospital adverse events: a systematic review. Qual Saf Health Care. 2008; 17: 216-223. 
Lubberding, S., Zwaan, L., Timmermans, D.R.M., Wagner, C. The nature and causes of unintended eventsf reported at 10 internal medicine departments. Journal of Patient Safety: 2011, 7(4), 224-231

\section{TABLES AND FIGURE}

TABLE 1. Categories of the Eindhoven Classification Model: Medical Version ${ }^{25,26}$

\begin{tabular}{|c|c|c|c|}
\hline Main Category & Subcategory & Code & Description \\
\hline \multicolumn{4}{|l|}{ Latent conditions } \\
\hline \multirow[t]{4}{*}{ Technical } & External & T-ex & $\begin{array}{l}\text { Technical failures beyond the control and responsibility of the } \\
\text { investigating organization. }\end{array}$ \\
\hline & Design & TD & Failures due to poor design of equipment, software, labels, or forms. \\
\hline & Construction & TC & $\begin{array}{l}\text { Correct design, which was not constructed properly or was set up } \\
\text { in inaccessible areas. }\end{array}$ \\
\hline & Materials & TM & Material defects not classified under TD or TC. \\
\hline \multirow[t]{5}{*}{ Organizational } & External & O-ex & $\begin{array}{l}\text { Failures at an organizational level beyond the control and responsibility } \\
\text { of the investigating organization, such as in another department or area } \\
\text { (address by collaborative systems). }\end{array}$ \\
\hline & $\begin{array}{l}\text { Transfer of } \\
\text { knowledge }\end{array}$ & $\mathrm{OK}$ & $\begin{array}{l}\text { Failures resulting from inadequate measures taken to ensure that } \\
\text { situational or domain-specific knowledge or information is transferred } \\
\text { to all new or inexperienced staff. }\end{array}$ \\
\hline & Protocols & OP & $\begin{array}{l}\text { Failures relating to the quality and availability of the protocols within the } \\
\text { department (too complicated, inaccurate, unrealistic, absent, or poorly } \\
\text { presented). }\end{array}$ \\
\hline & $\begin{array}{l}\text { Management } \\
\text { priorities }\end{array}$ & $\mathrm{OM}$ & $\begin{array}{l}\text { Internal management decisions in which safety is relegated to an inferior } \\
\text { position when faced with conflicting demands or objectives. This is a } \\
\text { conflict between production needs and safety. Example: decisions that } \\
\text { are made about staffing levels. }\end{array}$ \\
\hline & Culture & $\mathrm{OC}$ & $\begin{array}{l}\text { Failures resulting from collective approach and its attendant modes of } \\
\text { behavior to risks in the investigating organization. }\end{array}$ \\
\hline \multicolumn{4}{|r|}{ - } \\
\hline \multirow{7}{*}{$\begin{array}{l}\text { Knowledge-based } \\
\text { behavior }\end{array}$} & External & H-ex & $\begin{array}{l}\text { Human failures originating beyond the control and responsibility of the } \\
\text { investigating organization. This could apply to individuals in another } \\
\text { department. }\end{array}$ \\
\hline & $\begin{array}{l}\text { Knowledge-based } \\
\text { behavior }\end{array}$ & HKK & $\begin{array}{l}\text { The inability of an individual to apply their existing knowledge to a novel } \\
\text { situation. Example: a trained blood bank technologist who is unable to } \\
\text { solve a complex antibody identification problem. }\end{array}$ \\
\hline & Qualifications & HRQ & $\begin{array}{l}\text { The incorrect fit between an individuals training or education and a } \\
\text { particular task. Example: expecting a technician to solve the same } \\
\text { type of difficult problems as a technologist. }\end{array}$ \\
\hline & Coordination & HRC & $\begin{array}{l}\text { A lack of task coordination within a health care team in an organization. } \\
\text { Example: an essential task not being performed because everyone } \\
\text { thought that someone else had completed the task. }\end{array}$ \\
\hline & Verification & HRV & $\begin{array}{l}\text { The correct and complete assessment of a situation including related } \\
\text { conditions of the patient and materials to be used before starting the } \\
\text { intervention. Example: failure to correctly identify a patient by } \\
\text { checking the wristband. }\end{array}$ \\
\hline & Intervention & HRI & $\begin{array}{l}\text { Failures that result from faulty task planning and execution. Example: } \\
\text { washing red cells by the same protocol as platelets. }\end{array}$ \\
\hline & Monitoring & HRM & $\begin{array}{l}\text { Monitoring a process or patient status. Example: a trained technologist } \\
\text { operating an automated instrument and not realizing that a pipette } \\
\text { dispensing reagents is clogged. }\end{array}$ \\
\hline \multirow[t]{2}{*}{$\begin{array}{r}\text { Skill-based } \\
\text { behavior }\end{array}$} & Slips & HSS & $\begin{array}{l}\text { Failures in performance of highly developed skills. Example: a technologist } \\
\text { adding drops of reagents to a row of test tubes missing the tube or a } \\
\text { computer entry error. }\end{array}$ \\
\hline & Tripping & HST & $\begin{array}{l}\text { Failures in whole-body movements. These errors are often referred to as } \\
\text { "slipping, tripping, or falling." Examples: a blood bag slipping out of } \\
\text { one's hands or tripping over a loose tile on the floor. }\end{array}$ \\
\hline \multicolumn{4}{|r|}{ 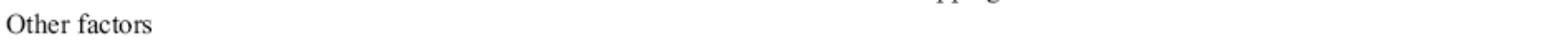 } \\
\hline Patient related & $\begin{array}{l}\text { Patient-related } \\
\text { factor }\end{array}$ & PRF & $\begin{array}{l}\text { Failures related to patient characteristics or conditions, which are beyond } \\
\text { the control of staff and influence treatment. }\end{array}$ \\
\hline Other & Unclassifiable & $\mathrm{X}$ & Failures that cannot be classified in any other category. \\
\hline
\end{tabular}


TABLE 2. Characteristics of Reported UEs

\begin{tabular}{lc}
\hline Characteristics & $\mathbf{n}(\%)$ \\
\hline Time of occurrence & \\
Weekdays & $488(84)$ \\
Weekends & $95(16)$ \\
Did the UE reach the patient? & \\
Yes & $389(62.2)$ \\
No & $182(29.1)$ \\
Unknown & $54(8.6)$ \\
UE type & \\
Collaboration with other departments & $76(12.2)$ \\
Medication & $262(41.9)$ \\
Diagnosis and treatment & $70(11.2)$ \\
Materials and equipment & $53(8.5)$ \\
Incorrect data and substitutions & $20(3.2)$ \\
Protocols and regulations & $56(9.0)$ \\
Collaboration with residents/specialists & $31(5.0)$ \\
Other & $57(9.0)$ \\
\hline
\end{tabular}


TABLE 3. Unintended Event Types With Examples

\begin{tabular}{|c|c|}
\hline UE Type & Example \\
\hline $\begin{array}{l}\text { Collaboration with } \\
\text { other departments }\end{array}$ & $\begin{array}{l}\text { Patient was admitted via the emergency } \\
\text { department but arrived at the IMD } \\
\text { without information on medical history } \\
\text { and resuscitation policy } \\
\text { Laboratory testing identified the patient's } \\
\text { glucose level to be very high } \\
\text { ( } 19.4 \mathrm{mmol} / \mathrm{l}) \text {, but the laboratory did } \\
\text { not inform the IMD by telephone } \\
\text { about this finding }\end{array}$ \\
\hline Medication & $\begin{array}{l}\text { Blood transfusion given through the } \\
\text { same intravenous line as medication } \\
\text { Administration of medication to the } \\
\text { wrong patient }\end{array}$ \\
\hline $\begin{array}{l}\text { Diagnosis and } \\
\text { treatment }\end{array}$ & $\begin{array}{l}\text { Patient received too much oxygen } \\
\quad \text { during } 3 \mathrm{~h} \\
\text { Wrongly adjusted dialyses monitor }\end{array}$ \\
\hline $\begin{array}{l}\text { Materials and } \\
\text { equipment }\end{array}$ & $\begin{array}{l}\text { Shortage of intravenous pumps } \\
\text { Patient injected with wrong needles }\end{array}$ \\
\hline $\begin{array}{l}\text { Incorrect data } \\
\text { and substitutions }\end{array}$ & $\begin{array}{l}\text { Patient sent to surgery with the wrong } \\
\text { medical record } \\
\text { Cardiopulmonary resuscitation cart came } \\
\text { for absent patient }\end{array}$ \\
\hline $\begin{array}{l}\text { Protocols and } \\
\text { regulations }\end{array}$ & $\begin{array}{l}\text { Glucose level was tested once, instead } \\
\text { of once an hour, as protocol suggests } \\
\text { Nonresuscitate policy noted in computer, } \\
\text { but not in the patient's medical record }\end{array}$ \\
\hline $\begin{array}{l}\text { Collaboration with } \\
\text { residents/specialists }\end{array}$ & $\begin{array}{l}\text { Specialist told the patient's Human } \\
\text { Immunodeficiency Virus (HIV) } \\
\text { diagnosis to family without permission. } \\
\text { Resident did not inform specialist } \\
\text { about the patient's wishes } \\
\text { Low-salt diet started by dietician without } \\
\text { consulting physician }\end{array}$ \\
\hline Other & $\begin{array}{l}\text { No information and explanation given to } \\
\text { the patient before starting chemo } \\
\text { treatment } \\
\text { Confused patient fell }\end{array}$ \\
\hline
\end{tabular}


Lubberding, S., Zwaan, L., Timmermans, D.R.M., Wagner, C. The nature and causes of unintended events reported at 10 internal medicine departments. Journal of Patient Safety: 2011, 7(4), 224-231

FIGURE 1. Box plot showing the frequencies of 20 root cause categories (the abbreviations match the description in Table 1) in 10 IMDs. Red diamonds indicate frequency means; horizontal lines within boxes are frequency medians; $50 \%$ of all observations are within the boxes; $95 \%$ are between the T-squares; small quadrangles are outliers (91.5 interquartile range). A large box means that there is a large variation between departments on the frequency of these root causes. Abbreviations are explained in Table 1.

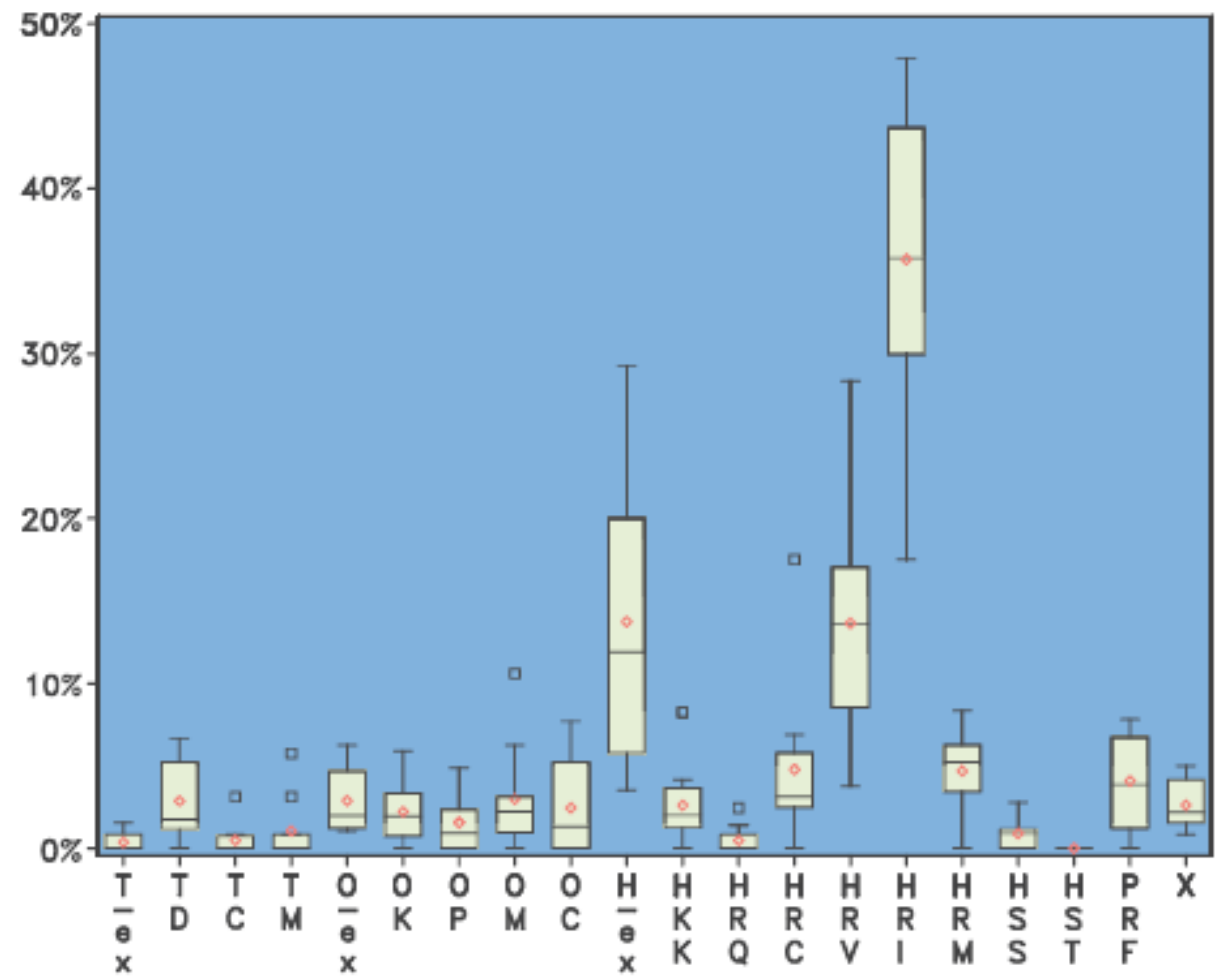

TABLE 4. Relation Between Root Causes and UE Types $(n=920)$

Collaboration

$\begin{array}{ccc}\begin{array}{c}\text { Collaboration } \\ \text { With Other }\end{array} & \begin{array}{c}\text { Diagnosis } \\ \text { and }\end{array} & \begin{array}{c}\text { Materia } \\ \text { and }\end{array}\end{array}$

UE Type/Root Departments, Medication, Treatment, Equipment, Substitutions, Regulations, Specialists,

\begin{tabular}{|c|c|c|c|c|c|c|c|c|c|}
\hline Causes & n $(\%)$ & n (\%) & n $(\%)$ & n $(\%)$ & n (\%) & n $(\%)$ & n (\%) & n $(\%)$ & n (\%) \\
\hline Technical & $2(2)$ & $15(4)$ & $4(4)$ & $22(30)$ & - & $1(1)$ & - & $3(4)$ & $47(5)$ \\
\hline Organizational & $15(14)$ & $43(10)$ & $13(13)$ & $15(20)$ & $2(7)$ & $10(13)$ & $4(8)$ & $7(10)$ & $109(12)$ \\
\hline Human & $87(79)$ & $332(82)$ & $81(81)$ & $32(44)$ & $28(90)$ & $67(85)$ & $43(88)$ & $35(49)$ & $706(77)$ \\
\hline Other & $6(5)$ & $15(4)$ & $2(2)$ & $4(6)$ & $1(3)$ & $1(1)$ & $2(4)$ & $27(37)$ & $58(6)$ \\
\hline Total & $110(100)$ & $405(100)$ & $100(100)$ & $73(100)$ & $31(100)$ & $79(100)$ & $49(100)$ & $72(100)$ & $920(100)$ \\
\hline
\end{tabular}


Lubberding, S., Zwaan, L., Timmermans, D.R.M., Wagner, C. The nature and causes of unintended events reported at 10 internal medicine departments. Journal of Patient Safety: 2011, 7(4), 224-231

TABLE 5. Consequences for the Patient After a UE $(n=389)$

No.

Consequences for the Patient Consequences \% of 389 UEs

\begin{tabular}{lrr}
\hline Suboptimal care & 174 & 44.7 \\
Extra interventions & 69 & 17.7 \\
Discomfort & 44 & 11.3 \\
Physical injury & 40 & 10.3 \\
Unknown consequence & 29 & 7.5 \\
Pain & 27 & 6.9 \\
Prolonged stay $(>24 \mathrm{~h})$ & 21 & 5.4 \\
Mental harm & 18 & 4.6 \\
Total & $422^{*}$ & 108.4 \\
\hline
\end{tabular}

*Unintended events could have multiple consequences.

FIGURE 2. Distribution of outcomes of UEs across UE types $(n=422)$.

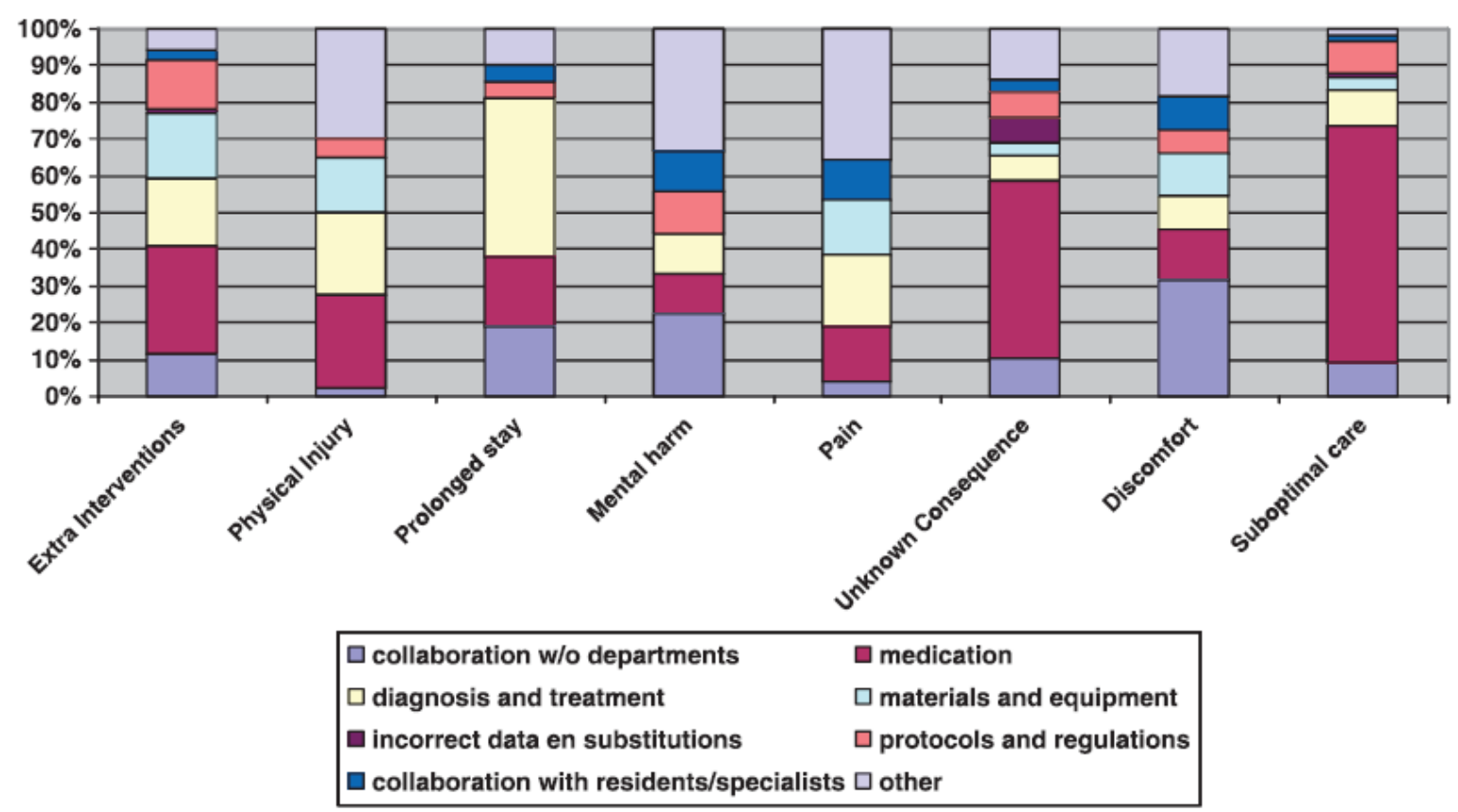

